\title{
Player Types: A Meta-synthesis
}

\author{
Juho Hamari \\ Game Research Lab, School of Information Science \\ University of Tampere, Finland \\ juho.hamari@uta.fi
}

Janne Tuunanen

Department of Industrial Engineering and Management Aalto University School of Science

janne.tuunanen@aalto.fi

\section{INTRODUCTION}

Recent developments in game business practices have especially elevated the need for distinguishing between types of players and play styles. For example, the new business models related to selling virtual goods has multiplied the amount of sold products within one game product or service as opposed to the retail sale of games. With the new business models game publishers subject the entire game and game design with its different value offerings to more accurate scrutiny in terms of marketing. Today, virtual items in games are no longer designed only to be an integral part of the finely tuned game balance. Instead, designers also have to think who would potentially be the customer for the virtual goods in question. These increasingly relevant questions that linger in the cross-roads of game design and marketing call for the use of marketing practices of segmentation and differentiation as a part of game design (Hamari \& Lehdonvirta 2010; Hamari 2011; Hamari \& Järvinen 2011). Another complementary development can be seen in the context of "gamification," where game design is increasingly being applied towards the goals of marketing (Huotari \& Hamari 2012; Hamari 2013). Hence, even in this context, understanding player types and motivations even becomes essential. 
This paper reviews different ways in which players have been typified in previous relevant literature and forms a comprehensive meta-synthesis of the identified types. The aim is to investigate and clarify the current state of research and to suggest further research avenues. The paper proceeds as follows: in the next section, we derive the theoretical underpinnings and the perspective of the paper to the player typologies. In the third section we outline the research process. The fourth segment combines previous literature on player typologies. The final section of the paper presents conclusions and proposes future avenues for research in player typologies.

\section{Ways to categorize the perspectives to player types}

Segmentation is a fundamental concept in marketing theory and literature, which has also always been a central part of marketing practices, if developed conceptually as such. In marketing theory, segmentation (and differentiation) can be traced back to beginning of 20th century. Shaw (1912) described differentiation as meeting (identified/ segmented) human needs as accurately as possible in such a way that it builds up demand in the targeted customer segments. In practice this implied that products were designed with certain end-users in mind, as opposed to mass marketing, where no aspects of the offering (e.g. the product itself or advertising) were differentiated towards a specific target group. Segmentation is the activity that aims to identify these customer groups (Kotler \& Keller 2006). The goal of segmentation is to better serve customers by being able to offer products that better match their needs and wants.

Later marketing literature has attempted to more accurately reach different modes of segmenting customers. The goal of segmentation is to identify groups of people that are as homogenous as possible, but that differ from each other in a significant way. In marketing literature, the following four overarching categories of segmentation have acquired an established standing: 
In geographic segmentation people are divided into groups based on their place of residence, for example country, county, city or so on. Considering the gaming context this could mean that gaming cultures differ between countries and continents.

In demographic segmentation consumers are categorized according to many descriptive features, such as age, gender, education, occupation or social status. These could be for example young male students or married middle aged women.

Psychographic segmentation is a more sophisticated approach, since it tries to group people according to their attitudes, interests, values and lifestyles. An example could be a social extrovert who enjoys meeting new people and likes surfing around the net.

Lastly there is behavioral segmentation which is an approach that tries to find patterns in consumers' behavior towards or with a product. Variables include benefits sought in a game, user status and usage rate. A gamer might play every now and then to relax and take their mind off work.

\section{Research process}

The present paper is a meta-analytical review of the previous works on player typologies. Meta-synthesis as a research approach attempts to interpretatively integrate results from different inter-related studies (Walsh \& Downe 2005). As such, the research process for the paper proceeded from literature search conducted in the most cited game studies journals and conference proceedings. More precisely; databases such as ACM Library, ScienceDirect and ProQuest were used as the main sources for previous studies. In addition some papers were found through searches in Google and Google Scholar. Terms/keywords such as "player types," "player typologies," "player motivations," "games and marketing" were used for finding related studies. Referring to papers' 
reference lists also led to previous studies on the topic.

As a result of this literature search, the selected papers were analyzed based on an author-centric approach (Webster \& Watson 2002) by connecting all the works to the main categories of segmentation in marketing theory (Kotler \& Keller 2006) as well as to list the different types of player typologies found in those studies (Table 1).

The next step of the process moved to a concept-centric analysis, where the findings were pivoted and categorized based on the found player typologies (Table 2). This approach enabled us to analyze the qualitative differences of player typologies in game studies research.

\section{Review of player typologies}

If we reflect upon the studies on player typologies, we can immediately notice in game studies the geographic or demographic aspects have not been of primary interest in research on player typologies, although there has been some research which has broken some of the preconceptions about the "player prototype." For instance, Williams et al. (2009) found that female players actually played more EverQuest 2 than their male counterparts. Although similar empirical research is being done on players, this paper will focus on papers that have attempted to conceptualize player typologies through their motivations, traits and behaviors. The studies on player typologies and categorization seem to have focused on psychographic and behavioral aspects. When it comes to game genres clearly some of them are more frequently covered than others. From Table 1 we can see that MMOs and online games are the most frequent. This may be problematic with respect toe generalizability of reviewed studies. 


\begin{tabular}{|c|c|c|c|c|c|}
\hline 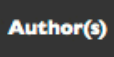 & Year & Basis & Methods & Presented player types & $\begin{array}{c}\text { Games in the } \\
\text { study }\end{array}$ \\
\hline Whang Chang & 2004 & Psychographic & $\begin{array}{l}\text { Quantitative - } \\
\text { factor analyses }\end{array}$ & $\begin{array}{l}\text { Single-oriented player, Community- } \\
\text { oriented player, Off-real world player }\end{array}$ & Lineage (MMO) \\
\hline Tseng & 2010 & Psychographic & $\begin{array}{l}\text { Quanticative - } \\
\text { factor analyses }\end{array}$ & $\begin{array}{c}\text { Aggressive gamer, Social gamer, Inactive } \\
\text { gamer }\end{array}$ & $\begin{array}{l}\text { Online games in } \\
\text { general }\end{array}$ \\
\hline Yee & $\begin{array}{l}2006 \\
2007 \\
2012\end{array}$ & Psychographic & $\begin{array}{l}\text { Quantitative - } \\
\text { factor analyses }\end{array}$ & $\begin{array}{l}\text { Achievement, Social, Immersion } \\
\text { (+subconstructs) }\end{array}$ & $\begin{array}{l}\text { EverQuest, Dark Age } \\
\text { of Camelot, Ultima } \\
\text { Online, and Star Wars } \\
\text { Galaxies (MMOs) }\end{array}$ \\
\hline $\begin{array}{l}\text { Zackariasson } \\
\text { et al. }\end{array}$ & 2010 & Psychographic & $\begin{array}{l}\text { Conceptual- } \\
\text { anajytical }\end{array}$ & $\begin{array}{l}\text { Progress \& provocation, Power \& } \\
\text { domination, Helping \& support, Friends \& } \\
\text { collaboration, Exploration \& fantasy, Story } \\
\text { \& escapism }\end{array}$ & $\begin{array}{l}\text { World of Warcraft } \\
\text { (MMO) }\end{array}$ \\
\hline Stewart & 2011 & $\begin{array}{c}\text { Behavioral } \\
\text { Psychographic }\end{array}$ & $\begin{array}{l}\text { Conceptual- } \\
\text { analytical }\end{array}$ & $\begin{array}{c}\text { Guardian/Achiever, RationaV/Explorer, } \\
\text { Idealist/Socialiser,Artisan/Killer, } \\
\text { Conqueror,Wanderer, Manager, Participant, } \\
\text { Hardcore, Casual }\end{array}$ & $\begin{array}{c}\text { The same ones as in } \\
\text { the previous studies } \\
\text { that it combines }\end{array}$ \\
\hline Bartle & 1996 & Behavioral & $\begin{array}{l}\text { Qualitative } \\
\text { observations } \\
\text { \& Conceptual- } \\
\text { analytical }\end{array}$ & Achiever, Explorer, Socialiser, Killer & MUDs \\
\hline Lazzaro & 2004 & Behavioral & $\begin{array}{c}\text { Conceptual- } \\
\text { analytical }\end{array}$ & $\begin{array}{l}\text { Easy fun, Hard fun, Altered states, The } \\
\text { people factor }\end{array}$ & Non-exclusive \\
\hline Drachen et al. & 2009 & Behavioral & $\begin{array}{l}\text { Quantitative } \\
\text { - clustering of } \\
\text { gameplay data }\end{array}$ & Veteran, Solver, Pacifist, Runner & $\begin{array}{l}\text { Tomb Raider: } \\
\text { Underworld }\end{array}$ \\
\hline$\underset{\text { Jacobs }}{\text { Ip }}$ & 2005 & Behavioral & $\begin{array}{l}\text { Quantitative - } \\
\text { factor analyses }\end{array}$ & Hardcore gamer, Casual gamer & Non-exclusive \\
\hline Kallio et al. & 2011 & Behavioral & $\begin{array}{l}\text { Triangulation of } \\
\text { quantitative and } \\
\text { qualitative data }\end{array}$ & $\begin{array}{l}\text { Social mentalities, Casual mentalities, } \\
\text { Committed mentalities }\end{array}$ & Non-exclusive \\
\hline $\begin{array}{c}\text { Hamari } \\
\text { Lehdonvirta }\end{array}$ & 2010 & Behavioral & $\begin{array}{c}\text { Conceptual- } \\
\text { analytical } \\
\text { combination } \\
\text { of qualitative } \\
\text { observations and } \\
\text { marketing theory }\end{array}$ & For example character levels and classes & $\begin{array}{l}\text { EverQuest, Habbo, } \\
\text { Puzzle Pirates, } \\
\text { World of Warcraft... } \\
\text { (Online games) }\end{array}$ \\
\hline Williams et al. & 2006 & $\begin{array}{c}\text { In-game } \\
\text { demographic }\end{array}$ & $\begin{array}{l}\text { Triangulation of } \\
\text { quantitative and } \\
\text { qualitative data }\end{array}$ & $\begin{array}{c}\text { Group centrality, Size of the guild, Type of } \\
\text { server, Faction }\end{array}$ & $\begin{array}{l}\text { World of Warcraft } \\
\text { (MMO) }\end{array}$ \\
\hline
\end{tabular}

Table 1: Studies on player types 
Especially gamers' motivation and in-game behavior has been covered extensively. Psychographic and behavioral typologies are however oftentimes challenging to distinguish because their are close to each other and therefore this categorization boils down to how these aspects have been observed in individual studies. For example, Bartle's (1996) types were originally interpretations of in-game behavioral patterns, but Yee (2002) took the types and used them as a basis for his motivation-based theory. Tseng (2010) did a psychographic analysis on gamer market, but one of his segments (Inactive gamers) encompasses the fact that many belonging to that segment are ex-gamers, which is actually a behavioral quality and not a psychological factor.

In the subsequent sections, we will review the papers. The review is divided into sections based on the perspective from which the players were categorized in the reviewed papers.

\section{Psychographic basis}

A prominent way in previous literature and in popular discussion has been to divide user population into hardcore and casual players, although it also has been criticized (e.g. Bateman et al. 2011) as too simplistic. In the reviewed literature these two types are treated either as a segmentation in itself (Ip \& Jacobs 2005) or as a part of a more comprehensive and multifaceted player type model (Stewart 2011). As opposed to casual players, what Ip \& Jacobs call hardcore players are people who are more dedicated to gaming in almost every way, demonstrating for example deeper knowledge of the industry, playing longer sessions more often and spending time discussing on game-related forums. Hardcore players also want to differentiate themselves from the mainstream and modify the game they are playing.

This model, as is, is of course very simplistic and generalizing if we are looking for player types that are as homogenous and descriptive as possible. It raises a question of where such a boundary could be drawn 
dividing players into more and less engaged ones. It is rather a scale of engagement; people have a degree of willingness to participate, make effort, pay money and so forth for different things. Perhaps modeling hard-coreness and casualness as a continuum would make some sense to this simple notion instead of understanding it as a dichotomous division. However, as games are complex services, it might be difficult to infer whether a person is a hardcore player within the context of the entire game or whether the players is merely interested in some parts of the game.

Stewart's (2011) claim is that hardcore behavior implies a significant level of immersion in the game world. According to Stewart, hardcore players require their games to be intellectually challenging and provide interesting and compelling adventurous experiences. Stewart suggests their preferred games are adventure and puzzle games. This might sound a bit surprising, as in popular discussion being hard-core is commonly related to younger males (Selwyn 2007) who play action or strategy games, which Stewart regards as games that casual players would prefer. This sounds interesting in the sense that many of today's adventure and puzzle games are differentiated mainly to the female market, and most of the action FPS games are seen as being designed towards masculine pursuits. Within the focus of this paper it is not of importance what different authors regard as preferred games for each segment. However, these varying notions of the "hardcoreness" seem to imply that there are multiple different interpretations about its meaning and that it remains as a central term in the popular literature and discussion (e.g. Juul's Casual Revolution, 2009).

The problem with dividing players into just two categories is that it seems to be filled with excess simplifications and even implausible speculation on, e.g. the suggested game types. The question of hardcore and casual gaming behavior does not seem to be black and white. Instead of being two clearly identifiable and explicit groups, there are 
those players - most if not all of the people in fact - who are positioned somewhere in between the two extremes. In the hardcore-casual analysis we are actually looking at a scale instead of a typology. In Stewart's case the types are part of a more extensive model but still, how can the division between hardcore and casual players be based on immersion, and solely immersion, in the first place? Can players be or not be just as immersed in a game of any genre? As also pointed out by other studies (e.g. Yee 2007; Kallio et al. 2011), immersion is a part of a much more complex set of motivational factors that guide player behavior, which should be taken into account in order to fashion a much more robust segmentation of players.

\section{Behavioral basis}

Behavioral segmentation is concerned with how player, users or customers behave with and within products and service. A study conducted by Drachen et al. (2009) looked at how a set of players completed the popular adventure game Tomb Raider: Underworld. They identified four different styles each with different playing patterns and solutions to specific problems and also a certain level of performance. By using game log information such as total number of deaths and completion time, the players were divided into the following four groups.

Veterans, as the name suggests, are the most seasoned players. They die fairly rarely and complete the game very quickly. Solvers take their time to solve the puzzles encountered during the play. Pacifists die mostly from enemies (as opposed to e.g. falling), and are fairly fast at completing the game. Runners are named according to their swift play-through of the game. Hamari \& Lehdonvirta (2010) compared the status hierarchies, player progression and affordances in games related to different ways of playing and found that the way games are often structured resemble the way in which marketers also think about customers. Games and especially persistent online games are commonly structured through character leveling in multiple different progres- 
sion metrics. This, the authors point out, is similar to how services and customer loyalty programs are structured in progressions in multitude of service dimensions and where different products can be differentiated to customers in each step of these progressions. Authors show that, in online games, virtual goods have also been targeted to certain players in certain stage of their progressions and style of play according to these aforementioned criteria.

This way the developers of the game could track, for example, the hardcore/casual continuum by operationalizing the in-game behaviors to the already established structures built into the game, such as levels and achievements. While Hamari \& Lehdonvirta (2010) do not explicitly propose a player typology they suggest methods and a framework for segmenting players via in-game behavior.

\section{The four archetypes}

Bartle (1996) is one of the most referenced authors with respect to player types. His player typology is based on observations about player behavior in Multi-User Dungeons (MUDs). According to Bartle's player types, there are two dimensions to playing, namely action vs. interaction and player-orientation vs. world-orientation. By determining one's position in each of the axes one could determine which of the resulting player types he or she fits in. First of the types is Achiever who prefers action and is world-oriented. An Explorer prefers interaction and is also world-oriented. Killers prefer action and are player-oriented. The last type is Socialiser who prefers interaction with other players. Figure 1 demonstrates these four types' relations to the player preferences and each other. 


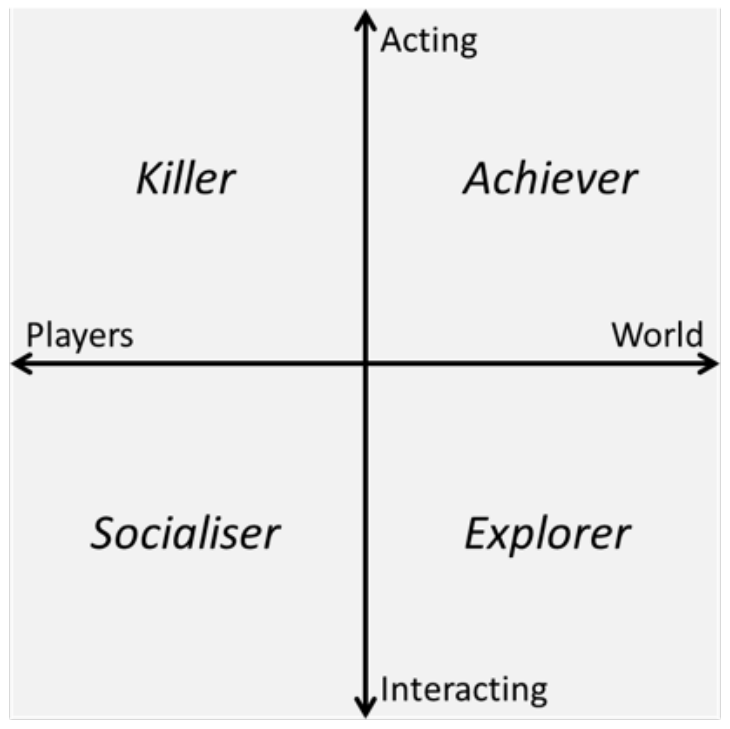

Figure 1: Bartle's player type axes

Bartle's player types have also received criticism for being too dichotomous and simplifying, although possibly a good tool for design purposes. The central criticism seems to be based on the notion that people's behavior and motivations can change in time and based upon the context, and therefore it can be difficult to pin-point exactly to what category a person belongs to. Another central point of criticism has been that in reality players have multiple motivations existing simultaneously but the magnitude of different motivations differ across players / player types. While Bartle's types are commonly used as a clear-cut categories, the frameworks consists of scales instead of nominal categories (Figure 1) and therefore, some of the criticism towards Bartle's types about being too strict are partly unwarranted. Therefore the dichotomous criticism seems to stem more from how Bartle's types have been used rather than from the original work. However, it would make sense to quantitatively test the relationship between the four types and scales of "interaction - action" and "player - world" orientations. Yee $(2002 ; 2006 ; 2007)$ has carried out a line of empirical studies 
about player motivations using Bartle's types as one of the references to ground the initial work. He used factor analysis to validate five motivational factors in his first article (Yee 2002). Putting emphasis on the later work we present only the latter results, which saw five initial factors transformed into three main factors, which altogether included ten sub-factors. According to Yee (2007), the three factors that motivate (online) gamers are Achievement, Social aspects and Immersion.

Yee's Achievement and Social factors resemble Bartle's world-orientation and interacting axes, but are not still perfectly analogous. Some underlying facets (or sub-factors) that Yee found to be applicable to Achievement weren't the same as in Bartle's heuristics. For example, Yee (2002) did confirm that achieving game goals was part of the Achiever type, but that it also includes the wish to gain power in the game setting. However, a will to beat the game was shown to be a motivating factor for gamers. Bartle did not cover Immersion explicitly, but Yee found that immersing oneself to the game world is one major motivation for play.

These motivational factors are not exactly player types, like Bartle's, but they can be seen as a possible basis for psychographic segmentation based on motivations for play. The relationship between psychographic and behavioral factors is that the latter are partly a manifest because of the former and thus as no surprise the conceptualizations of both end up being very similar. If a person reports having a motivation for achievement, it is expected that studies that investigate the actual behavior, found connections to these motivations. Another interesting point about player typologies is that when game developers started to use them as tools in game design, the games gradually started having the exact same dimensions that are found that people like. For example, some game designers have made sure that the game has the elements that resonate with every player type in Bartle's typology (based on discussion with several game designers). 
Stewart (2011), in his conceptual piece, combined the Bartle's behavioral typology with several different conceptualizations, some of which are not even related to players, but rather to system abstractions. The author's goal seemed to be to force as many different concepts into only four dimensions and thus resulting in many strange and unfitting combinations (see source for more details). In an interesting question remains, however; would these different traits/motivations correlate also if studied empirically?

Zachariasson et al. (2010) merge Yee's motivational factors and identity construction based upon towards self and others. The resulting can be described as Progress \& provocation, Power $\&$ domination, Helping \& support, Friends \& collaboration, Exploration \& fantasy, Story \& escapism. The first two relate to Yee's Achievement, second two are under Social, and so the latter two stem from the Immersion factor. Because the typology is based on Yee's model, the outcome is very similar to both Yee and Bartle including the concepts of achieving goals, being social while playing and immersing oneself in the game.

\section{Other approaches}

There are also other approaches to explaining possible motivations behind gamers. Tseng (2010) approached the question with two motivational factors, namely the need for exploration and the need for conquering. The need for exploration entails not only the obvious exploration, but also social and achievement orientations. Need for conquering then quite logically consists of attributes linked to Bartle's Killertype, i.e. enjoying killing others and seeing their misery. The statements used in the survey obviously point to these four archetypes established earlier. After using factor analysis on his data Tseng divided players into three segments accordingly. Aggressive gamers scored highest on both factors. Social gamers score high on need for exploration but lowest on need for conquering. Inactive gamers score some- 
where in-between, that is, lowest on first factor and in the middle on the latter factor. The naming of Social gamers segment is a bit curious because the exploration factor included other aspects of gameplay also. But in this case, "exploration" means also for example discovering new relationships, so the segment can be concluded to be inclined to social activities.

Based on their study on lifestyles that people lead in the online game Lineage, Leo Whang \& Chang (2004) divided the population of an online game into single-oriented, community-oriented and "off-real world player." According Whang \& Chang, single-oriented players view any game as a single player game, and as a result prefer to act alone even in a game with rich social features. They do not want to be interfered with. Community-oriented players, on the contrary, represent the part of a player community which appreciates the social aspect of playing and embrace it with great enthusiasm. This group is similar to the type or motivation which is identified as "social" in many studies. The off-real world type of player aims to achieve personal gains in the game world by any means necessary and is very anti-social. This type of player is also discriminative in the game world, unlike the single-oriented player. Off-real world players also have a tendency to play a role instead of appearing as their real world self. Off-real world players can therefore be equated with Yee's Immersion motivation, but also Bartle's Killer type. Community-oriented is clearly the Social type. Single-oriented seems to match the Achiever kind of player.

Kallio et al. (2011) discard altogether the traditional type theories. Their goal was to fashion a gamer mentality heuristic which would be independent of any domain or genre. They suggest that the play style depends on so many variables, such as the company in which the game is played and time available for playing, that placing gamers in rigid "boxes" doesn't work. The mentalities that they suggest are 
divided into three main categories each with three sub-categories. The first set of three is Social mentalities i.e. Playing with Children, Playing with Mates and Playing for Company. The second one is Casual mentalities i.e. Killing Time, Filling Gaps and Relaxing. The last one is called Committed mentalities and it consists of Gaming for Fun, Immersive Play and Gaming for Entertainment. These sets quite directly correspond to aforementioned factors, such as gaming intensiveness (hardcoreness - casualness), social motivations, and immersion.

\section{In-game demographics}

Game design and game mechanics are a fairly new and industry-specific way of looking at marketing. Not only do they give relevant data on the player, game designers as marketers can be for once proactive about segmentation and actually affect the way segments are formed within the game. This has been studied from the viewpoints of both real-world products (Zackariasson et al. 2010) and digital items (Hamari \& Lehdonvirta, 2010). Zackariasson, in fact, suggests that marketers might have better luck targeting their products towards the avatars instead of players.

As mentioned in the previous section, Hamari \& Lehdonvirta proposed a two-dimensional segmentation related to the game design. The vertical component would correspond to the progress of a character, such as advancing in levels could be accounted in part for being committed to the game i.e. gaming intensity, and in part for drive for progressing, which would be related to achievement as a motivation. As the horizontal component there are different avatar classes, generic examples being for example warrior and wizard, and professions, such as blacksmith and tailor, to pursue. This is in-game demographic segmenting. According to Hamari \& Lehdonvirta differentiated digital products could be developed and marketed to match the needs of players of given dedication and orientation to the game. Williams et al. (2006) studied the meaning and value of guilds in 
World of Warcraft. The authors do not offer a thorough player typology or suggest a way to segment players explicitly; they identified many game design related features that work as good indicators as to what player's preferences and orientations are. For example what they found was that players in specific role playing servers play the game in a completely different fashion than people who are less interested in posing as someone fictional. Role players are deeply immersed in the game world. Also, smaller guilds are usually more tightly knit together than larger ones, meaning that the members are more active, or more social if you will. Also, the type and size of the guild is related to one's ambitions of achieving end-game content, since only larger guilds have the resources to pursue such a challenge which requires a considerable group force.

\section{Typologies combined: a concept-centric summary}

The findings and the different concepts discussed in the analysis section along with responding segments and other typologies are summarized and presented in Table 2. The "Concepts" are common ideas that recurred across several papers. The concepts were given names that reflect the common ideas discussed in the papers.

Most covered concepts in reviewed literature seem to be Achievement and Sociability. The bottom three concepts Domination, Immersion and In-game demographics appear the least. Especially In-game demographics could be found only in few papers. 


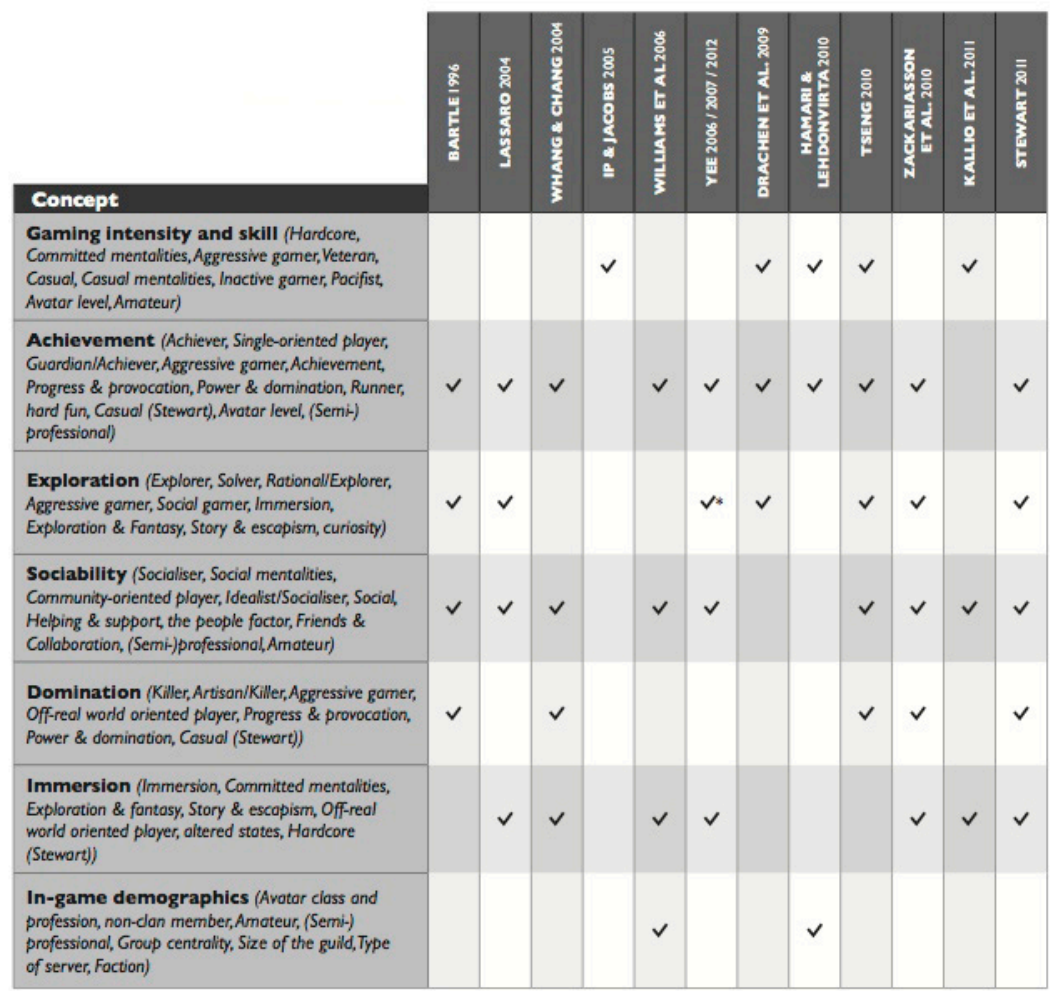

* Included in Immersion

Note: Although the papers are covered here in the same table, it does not imply that they would be directly comparable with respect the their scope.

Table 2: Concept-centric listing of the player typologies in game research

\section{Criticism on player types}

Any abstraction that simplifies a phenomena can be criticized for that fact. Player typologies seems to fall within easily criticized abstractions for several reasons: 1) they are commonly discussed as if the types were dichotomous, whereas in reality any such psychological factors ought to be measured and discussed as scales (see Nunnally 1978), 2) player types are an abstraction of an abstraction: a player type essentially re- 
fers to an emphasis in the set of motivations or behaviors. Typologies, such as Bartle's, should be understood as an archetypal categorization, where the types represent a player type whose certain motivations and behaviors are stronger than in other player types. For example, an explorer type might be more curious, explore more and spend more time weighting different alternative courses of action. Other motivational and behavioral dimensions are here then assumed neutral. 3) Motivations and behaviors of a player might not fully transfer between different types of games, however, this does NOT render measuring player motivations and behaviors useless, but on the contrary, calls for a systematic investigation between game types. This situation would indeed call for unified measurement scales in order to investigate differences over game genres. 4) Typifying gamers can be seen as counter-productive from a phenomenological perspective where the aim is not so much in generalizability and comparisons but rather in investigating player experience on a richer level. However, in a more structured qualitative approach, player typologies may prove a useful aid. 5) Furthermore, as player types are described and defined in variety of ways in literature, it has been a somewhat of a subjective step to codify different presented types within the categories in the paper. Hence, a limitation of this paper as well as the entire research on player types is its manifoldness with respect to the different perspectives (archetypes vs. scales - traits vs. motivations vs. benefits vs. behaviors). Therefore, further studies could elaborate even more on comparability of player typologies. 6) It is also questionable whether we even need frameworks that are specific to playing or whether game studies should simply adopt existing frameworks from the larger context of psychology. It seems that both approaches exist, since some typologies have been adapted from existing personality types and some (such as Bartle) have been conceptualized based on observations of players. 


\section{Conclusions \& Discussion}

The field of study in player types is perhaps surprisingly uniform. The current studies could be synthesized into five key dimensions pertaining to motivations of play/orientation of the player: Achievement, Exploration, Sociability, Domination, and Immersion. Additionally, in relevant literature, notions of how Intense the mode of play, was commonly articulated as continuum or dichotomy between hardcoreness and casualness were largely present in most of the studies. Furthermore, some studies have suggested using "in-game demographics," such as class and progression as one basis for typifying players through behavioral measurement.

Even though the research has focused largely on well-defined player types, there are also those who question the approach of categorizing players (e.g. Kallio et al. 2011). Indeed, "player type" can give the impression that a player would strictly belong to a certain type. However, this study would like to highlight that whether player types were referred to as nominal or as ordinal in previous studies, the types will nevertheless provide ground for further measurements of player traits, attributes and motivations as well as hence help in forming a more refined understanding about them. At this stage of the research continuum, a couple of different perspectives to player types mix together, such as types in accordance to motivations of play (Yee 2007; 2012), gaming mentalities (Kallio et al. 2011), traits of the player (Bateman et al. 2011), their behavior and self-selected in-game demographics. The aim in this study was to bring these separate perspectives together, which all have commonly shared a common nominator: "player types."

Our findings also show that the amount of dimensions pertaining to player types is rather low in the respective literature and very much based on Bartle's (1996) original work. In addition to the Bartle's achiever, explorer, socializer and killer, only immersion oriented play 
as a qualitative mode of play/player orientation could be found on the same abstraction level from other literature. Outside these psychographic types, previous literature has also suggested using in-game demographic factors (Hamari \& Lehdonvirta 2010; Zackariasson 2011) and gaming intensity (Ip \& Jacobs 2005; Drachen et al. 2009; Hamari $\&$ Lehdonvirta 2010; Tseng 2010; Kallio et al. 2011). Some works, such as Yee (2006) and Kallio et al. (2011) do provide sub-dimension to the higher abstraction level player motivation and mentalities; however, on this abstraction level the studies do not add additional dimensions of player types. We were surprised for instance, that within this stream of literature, there were no mentions of such motivation to play such as sensory enjoyment, aesthetic enjoyment, playfulness or utilitarian gaming motivations, such that professional eSports player might have for example.

These findings suggests that we have not yet exhausted the study on identifying player types from perspectives of motivations, ways in which players play or how they can otherwise be segmented according to their behavior within and around games. Therefore, further research on identification and abstraction of player types is still a potential way forward. This suggests that the research stream on player types could benefit from further synthesis, validation and comparative studies. Parallel with this work we call for constructing more measurement scales for all the found player types in order to quantitatively use the types in further research. Yee (2012) has started this work by developing scales for achievement, immersion and social motivations. Many of the typologies are behavioral and attempt to explain the relationship between the player and the game in order to understand them. Working back from actual behavioral use data, connecting it to psychological factors and mapping their correspondences could provide a potential avenue for further research, especially because games offer effective ways to measure actual user behavior in parallel with conducting psychometric investigations. 


\section{Implications to game studies}

For quantitative game studies, the results of this paper give qualitative validation and summary on found player traits and pre-disposition from a bottom-up perspective. Thus, the results help further quantitative game studies in developing further measurement scales for studying players and relationships of different player traits with different player behavior within games and gamification. Most of the player typologies have been built based upon observation within MMOs and other online games. Therefore, further studies could employ these measures for studying differences across game types, platforms and play contexts.

For qualitative game studies, the results of this paper might not be as fruitful for further research agendas, since qualitative studies should strive for investigating more fine-grained phenomena rather than examining players only as seen through pre-defined factors. However, one should note that most work on player types thus far has emanated from qualitative works regardless. The name "player type" is misleading in the sense that of course no player falls within any one of the types defined in the literature. The results, however, do summarize the ongoing (mostly qualitative) research on player types. Furthermore, the identified player types could act as a point of departure in qualitative studies for investigating player experiences on a finer grained level.

One especially interesting further inquiry could be in investigating the feedback loop of how established player typologies affect the design of games and how they further strengthen the common ways to play. This might create a situation where gamer typologies are self-fulfilling and self-validating. In other words, designing a game for certain player types might result in the same player types ending up being the dominant ones within the game as well if measured via behavior. Game designers have made sure that the game has the elements that 
resonate with every player type in Bartle's typology (based on several discussions with game developers).

In contextual terms, player typologies, and game research in general, could provide points of departure for studies outside what can traditionally be seen as games. For example, the use of gamification and persuasive games is becoming more commonplace in differing contexts (Hamari et al. 2014), such as commerce (Hamari 2013), organizations (Jung et al. 2010), healthy lifestyle (e.g. Hamari \& Koivisto 2013) and marketing (Huotari \& Hamari 2012). The studies on how people play and what kinds of motivations they have can help related research in other realms.

\section{Implications to game design and marketing}

Although the research stream on player types in not directly associated with marketing literature, player types has been a central interest to game companies with regards to the design and marketing. Furthermore, the process of identifying user groups could be compared to that of marketing and segmentation. Techniques applied are those used in segmentation as well (e.g. factor analyses). Some typologies that were covered have potential to be used as a basis for segmentation. For example Yee's $(2007 ; 2012)$ motivational factors could act as such a basis for psychographic segmentation. Some authors, on the other hand, have based their typologies directly on marketing theory. Hamari \& Lehdonvirta (2010); Hamari \& Järvinen (2011); Zackariasson et al. (2010) and Tseng (2010) refer to marketing theory and discuss segmentation in their papers. The results of this paper could help game companies better understand their clientele, and the results could be used as a starting point for a more thorough and "exact" segmentation. In addition, in relation to game design, designers now have in their knowledge the common behavioral patterns and motivational factors of players and can design and develop their games accordingly. Furthermore, established psychometric measurement scales can further 
be used in predicting for example the use and purchase behavior within games between players with different motivational orientations.

\section{References}

Bartle, R. "Hearts, Clubs, Diamonds, Spades: Players Who Suit MUDS.” 1996. http://www.mud.co.uk/richard/hcds.htm.

Bateman, C., Lowenhaupt, R., \& Nacke, L. "Player Typology in Theory and Practice." In Proceedings of DiGRA 2011 Conference: Think Design Play. Hilversum, Netherlands, September 14-17, 2011.

Drachen, A., Canossa, A., \& Yannakakis, G., N. "Player Modeling using Self-Organization in Tomb Raider: Underworld." In Proceedings of the IEEE Symposium on Computational Intelligence and Games. Milan, Italy, September 7-10, 2009.

Hamari, J. "Perspectives from behavioral economics to analyzing game design patterns: loss aversion in social games." In Proceedings of the Social Games Workshop, CHI2011. Vancouver, Canada, May 7-12, 2011.

Hamari, J., \& Järvinen, A. "Building Customer Relationship through Game Mechanics in Social Games." In M. Cruz-Cunha, V. Carvalho \& P. Tavares (Eds.), Business, Technological and Social Dimensions of Computer Games: Multidisciplinary Developments. Hershey, PA: IGI Global.

Hamari, J., \& Lehdonvirta, V. "Game design as marketing: How game mechanics create demand for virtual goods." In International Journal of Business Science and Applied Management, vol 5 no. 1 (2010):14-29.

Hamari, J. "Transforming Homo Economicus into Homo Ludens: A Field Experiment on Gamification in a Utilitarian Peer-To-Peer Trading Service." In Electronic Commerce Research and Applications, no.12 (2013), 236-245.

Hamari, J., \& Koivisto, J. "Social Motivations to Use Gamification: An Empirical Study of Gamifying Exercise." In Proceedings of the 
21st European Conference on Information Systems. Utrecht, Netherlands, 5-8, June, 2013.

Huotari, K., \& Hamari, J. "Defining Gamification - A Service Marketing Perspective." In Proceedings of The 16th International Academic Mindtrek Conference, Tampere, Finland, 3-5 October, 2012.

Hamari, J., Koivisto, J., \& Sarsa, H. "Does Gamification Work? - A Literature Review of Empirical Studies on Gamification." In Proceedings of the 47th Hawaii International Conference on System Sciences, Hawaii, USA, 6-9, January, 2014.

Ip, B., \& Jacobs, G. (2005). "Segmentation of the games market using multivariate analysis." Journal of Targeting,Measurement and Analysis for Marketing, vol. 13 no. 3 (2005):275-287.

Jung, J.H., Schneider, C., \& Valacich, J. "Enhancing the motivational affordance of information systems: The effects of real-time performance feedback and goal setting in group collaboration environments." In Management Science vol. 56 no. 4. (2010): 724-742

Juul, J. A Casual Revolution: Reinventing Video Games and Their Players. Cambridge, MA: MIT Press, 2009.

Kallio, K.P., Mäyrä, F., \& Kaipainen, K. (2011). "At Least Nine Ways to Play: Approaching Gamer Mentalities." In Games and Culture vol. 6 no. 4 (2011): 327-353.

Kotler, P., \& Keller, K. Marketing Management (Twelfth Edition). NJ: Prentice Hall, 2006.

Lazzaro, N. (2004). "Why We Play Games: Four Keys to More Emotion Without Story." In Game Developers Conference. San Jose, USA, March 22-26, 2004.

Lin, C-F. (2002). "Segmenting customer brand preference: demographic or psychographic." In Journal of Product \& Brand Management vol. 11 no. 4 (2002):249-268.

Nunnally, J.C. Psychometric Theory (2nd ed.). New York: McGraw-Hill, 1978. 
Selwyn, N. "Hi-tech = Guy-tech? An exploration of undergraduate students' perceptions of information and communication technologies." In Sex Roles vol. 56 (2007):525-536.

Stewart, B. "Personality And Play Styles: A Unified Model." In Gamasutra 2011. http://www.gamasutra.com/view/feature/6474/personality_and_play_styles_a_.php.

Tseng, F-C. "Segmenting online gamers by motivation." Expert Systems with Applications, vol. 38 (2010): 7693-7697.

Tuunanen, J., \& Hamari, J. "Meta-synthesis of Player Typologies." In Proceedings of Nordic DiGRA 2012 Conference: Local and Global - Games in Culture and Society, Tampere, Finland, 6-8 June, 2012.

Walsh, D., \& Downe, S. "Meta-synthesis method for qualitative research: a literature review." In Journal of Advanced Nursing, vol. 50 no. 2 (2005): 204-211.

Webster, J., \& Watson, R.T. "Analyzing The Past to Prepare for the Future: Writing a Literature Review." In MIS Quarterly vol. 26 no. 2 (2002).

Whang, L. S., \& Chang, G. "Lifestyles of Virtual World Residents: Living in the On-Line Game 'Lineage”. In CyberPsychology \& Behavior, vol. 7 no. 5 (2004): 592-600.

Williams, D., N. Ducheneaut, , L. Xiong, , Y. Zhang,, N. Yee, \& E. Nickell. (2006). "From tree house to barracks: The social life of guilds in World of Warcraft." In Games \& Culture vol. 1 no. 4(2006): 338-361.

Williams, D., M. Consalvo, S. Caplan, \& N. Yee "Looking for Gender: Gender Roles and Behavior Among Online Gamers.” Journal of Communication, vol. 59 (2009): 700-725.

Yee, N. "Facets: 5 Motivation Factors for Why People Play MMORPG's." 2002. Available at: http://www.nickyee.com/facets/home.html.

Yee, N. "The Demographics, Motivations and Derived Experiences of Users of Massively Multi-User Online Graphical Environments." 
In PRESENCE: Teleoperators and Virtual Environments, no. 15 (2006): 309-329.

Yee, N. (2007). "Motivations of Play in Online Games." In Journal of CyberPsychology and Behavior, no. 9 (2007): 772-775.

Yee, N., N. Ducheneaut, \& L. Nelson. "Online gaming motivations scale: development and validation." In Proceedings of the 2012 ACM annual conference on Human Factors in Computing Systems, Austin, USA, 5-10, May, pp. 2803-2806. ACM 2012.

Zackariasson, P., N. Wåhlin, \& T.L. Wilson. "Virtual Identities and Market Segmentation in Marketing in and Through Massively Multiplayer Online Games (MMOGs).” In Services Marketing Quarterly no. 31 (2010): 275-295. 